\title{
Perils of police action: a cautionary tale from US data sets
}

\author{
Ted R Miller, ${ }^{1,2}$ Bruce A Lawrence, ${ }^{1}$ Nancy N Carlson, ${ }^{3}$ Delia Hendrie, ${ }^{4}$ Sean Randall, ${ }^{2}$ \\ Ian R H Rockett, ${ }^{5}$ Rebecca S Spicer ${ }^{1}$
}

${ }^{1}$ Pacific Institute for Research and Evaluation, Calverton, Maryland, USA

${ }^{2}$ Faculty of Health Sciences, Centre for Population Health Research, Curtin University, Perth, Australia ${ }^{3}$ University of the District of Columbia, Washington DC, USA

${ }^{4}$ School of Public Health Curtin University, Perth, Australia

${ }^{5}$ Department of Epidemiology and Injury Control Research

Center, School of Public Health, West Virginia University, Morgantown, West Virginia, USA

\section{Correspondence to} Dr Ted R Miller, Principal Research Scientist, Pacific Institute for Research and Evaluation, 11720 Beltsville Drive, Suite 900, Calverton, MD 20705, USA; miller@pire.org

Received 10 March 2016 Revised 12 April 2016 Accepted 15 May 2016

\section{CrossMark}

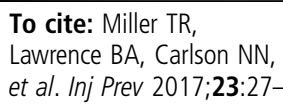

ABSTRACT
Objective To count and characterise injuries resulting from legal intervention by US law enforcement personnel and injury ratios per 10000 arrests or police stops, thus expanding discussion of excessive force by police beyond fatalities.

Design Ecological.

Population Those injured during US legal police intervention as recorded in 2012 Vital Statistics mortality census, 2012 Healthcare Cost and Utilization Project nationwide inpatient and emergency department samples, and two 2015 newspaper censuses of deaths.

Exposure 2012 and 2014 arrests from Federal Bureau of Investigation data adjusted for non-reporting jurisdictions; street stops and traffic stops that involved vehicle or occupant searches, without arrest, from the 2011 Police Public Contact Survey (PPCS), with the percentage breakdown by race computed from pooled 2005, 2008 and 2011 PPCS surveys due to small case counts.

Results US police killed or injured an estimated 55400 people in 2012 (95\% Cl 47050 to 63740 for cases coded as police involved). Blacks, Native Americans and Hispanics had higher stop/arrest rates per 10000 population than white non-Hispanics and Asians. On average, an estimated 1 in 291 stops/arrests resulted in hospital-treated injury or death of a suspect or bystander. Ratios of admitted and fatal injury due to legal police intervention per 10000 stops/arrests did not differ significantly between racial/ethnic groups. Ratios rose with age, and were higher for men than women. Conclusions Healthcare administrative data sets can inform public debate about injuries resulting from legal police intervention. Excess per capita death rates among blacks and youth at police hands are reflections of excess exposure. International Classification of Diseases legal intervention coding needs revision.

\section{BACKGROUND}

Of necessity, police sometimes injure or kill a felon to protect the public or themselves. Police use of undue force is an enduring tinderbox issue in America. ${ }^{1-4}$ In the aftermath of the Civil War, adoption of the 14th Amendment to the Constitution and 18 US Code Sections 241 and 242 and 42 US Code Section 1983 provided protections against police use of excessive force or other punishment without due process of law. A unanimous US Supreme Court affirmed the applicability of these protections to the policeabetted murder of civil rights workers Schwerner, Chaney and Goodman in Mississippi in 1964. ${ }^{5}$

Police instructors often teach officers about force continuums where police response progressively adjusts to match the changing level of suspect resistance. ${ }^{6-8}$ Some have started teaching de-escalation techniques. ${ }^{9}$

Legal protections and training, however, cannot prevent every abuse of power or police loss of control out of anger or fear. Recently, US press and public outcry protested police shootings of unarmed citizens and potentially negligent deaths in police custody. ${ }^{10}$ Discussion has focused almost exclusively on fatalities, driven by Federal Bureau of Investigation $(\mathrm{FBI})^{11}$ statistics on deaths due to legal intervention by law enforcement personnel (hereafter called legal police intervention), and by newspaper-compiled censuses that reveal the FBI reports omit half the fatalities. ${ }^{12} 13$ Periodic Police Public Contact Surveys (PPCS) also find that blacks are more likely than whites or Hispanics to experience physical force during a police-initiated stop. ${ }^{14}$

Vital statistics and healthcare claims administrative data sets contain a wealth of untapped information about the extent and nature of suspect/bystander injury resulting from legal police intervention. The International Classification of Diseases (ICD), 9th and 10th revisions, define legal intervention as injuries inflicted by the police or other law-enforcing agents ... in the course of arresting or attempting to arrest lawbreakers, suppressing disturbances, maintaining order, and other legal actions'. Some of these injuries involve undue force.

This article uses ICD-coded national data to close information gaps. It estimates non-fatal injuries resulting from legal police intervention. It adds insights by comparing injuries from legal police intervention versus assault and using police arrest and stop counts as denominators to compute injury ratios.

\section{METHODS}

We used SAS V.9.4 to analyse 2012 unit record data on non-fatal injury from the Healthcare Cost and Utilization Project (HCUP) Nationwide Inpatient Sample (NIS) and Nationwide Emergency Department Sample (NEDS). ${ }^{15} 16$ We extracted and cleaned injury cases from NIS and NEDS following published procedures, ${ }^{17}$ and coded the injuries by body region and by Abbreviated Injury Severity threat to life using ICDmap90 software. ${ }^{18}$ Legal police intervention cases were identified by ICD, 9th Revision, Clinical Modification (ICD9-CM) external cause codes E970-E977. To identify taser injuries, we searched for an electroshock diagnosis in the case (ICD9-CM diagnosis 994.8). We estimated lifetime medical costs for each case using methods and cost factors from the online 
WISQARS (Web-based Injury Statistics Query and Reporting System) model. ${ }^{19}$ Unlike ICD10, WISQARS non-fatal data ${ }^{20}$ code intent separately from mechanism. Multiyear WISQARS counts had wide CIs and were too thin to provide stable estimates by demographics or for many mechanisms. They did yield insight into mechanisms where the ICD10-CM coding system that replaced ICD9-CM in 2015 inappropriately lacks legal police intervention codes.

\section{Fatalities}

Deaths from legal police intervention are underidentified or undercounted in US Vital Statistics, FBI Supplemental Homicide Reports, and Bureau of Justice Statistics Arrest-Related Deaths programme data. ${ }^{21-24} \mathrm{~A}$ modified capture-recapture modelling approach suggested each captured $46-49 \%$ of these fatalities, ${ }^{21} 24$ while comparisons with National Violent Death Reporting System (NVDRS) data for 16 states suggested a $48-58 \%$ capture. ${ }^{24}$ The Washington Post used daily press searches and supplemental crowdsourcing to track US firearm deaths due to police action during 2015, verifying and detailing each identified death. ${ }^{12}$ The Guardian ${ }^{25}$ compiled a similar list that added nonfirearm deaths, as well as deaths in custody and deaths in crashes where police vehicles were at fault. ${ }^{13}$ Consistent with the capturerecapture models, both found about twice as many legal police intervention incidents as the three national reporting systems. Several epidemiological studies found systematically searched newspaper accounts a credible injury data source. ${ }^{26-30}$ We therefore relied primarily on homicide estimates by demographic group from the Guardian data, ${ }^{25}$ excluding 41 deaths in custody (primarily cardiovascular or other health crises) and 33 in crashes. For half of the 24 cases with missing demographic data, we back-filled this information from the Washington Post listing.

\section{Demographic tabulations}

We tabulated data by victim age group, sex, race and Hispanic ethnicity, rurality, mechanism (eg, firearm), and, for hospital admissions, by alcohol and drug involvement of the person injured. All tables were run in SAS V.9.4., applying sample weights to the HCUP data, which are public use samples of approximately $20 \%$ of all US discharges.

Data deficits limited our analysis of race-ethnicity. NEDS cannot supply nationally representative race-ethnicity estimates because many states do not either identify race and ethnicity or collect emergency department (ED) data centrally. We therefore restricted the race-ethnicity analysis to fatal and hospital-admitted injuries.

\section{Denominators}

As denominators for producing injury ratios, we used the sum of FBI-tabulated arrest data, adjusted for non-reporting, ${ }^{31}$ and 2011 PPCS-based national estimates (which we computed using STATA V.11) of police street stops without arrest and of traffic stops where a person or vehicle was searched but the person stopped was not arrested. ${ }^{32}$ In 2012, FBI arrest data largely excluded Alabama, the District of Columbia, Hawaii, Illinois (except Chicago and Rockford) and New York City, and lacked demographic detail for Florida. Online search provided arrest data that we manually added for three of these jurisdictions: Hawaii, ${ }^{33}$ Alabama $^{34}$ and New York City. ${ }^{35}{ }^{36}$ We adjusted the remaining FBI-reported data to US estimates under the assumption that arrest rates by region for the $82 \%$ of the US population covered by the FBI data and our supplements were representative of arrest rates in those regions in frequency and demographics. The FBI only began collecting Hispanic origin in 2013 arrest data, with reporting much more complete in 2014 than 2013. We supplemented the 2014 data $^{11}$ with a racial breakdown for New York City. ${ }^{37} 38$ Our analyses classified all minority Hispanics (eg, five of the deceased) by their minority race. We assumed white Hispanics would constitute the same $28.6 \%$ of arrested whites in 2012 as in 2014. Although we used 2011 stop counts, because 2011 PPCS data were sparse for some racial groups, we distributed them using an average percentage breakdown by race that we computed from pooled 2005, 2008 and 2011 surveys. $^{32} 39$ To test significance of ratio differences, we computed pairwise bivariate CIs between related demographic categories (eg, male vs female).

\section{RESULTS}

The Guardian $^{25}$ counted 1069 deaths from police intervention during 2015, including 1015 by firearms. By comparison, the Washington Post ${ }^{40}$ firearm death count was 990 and Bureau of Labor Statistics capture-recapture modelling estimated annual deaths due to legal police intervention averaged 928 in 20032009 and $2011 .^{21}$

In 2012, an estimated 55400 people were killed or hospitaltreated in legal police intervention incidents (table $1,95 \% \mathrm{CI}$ 47050 to 63740 ). About 2\% (1063) suffered fatal injuries, 5\% (2665, 95\% CI 2386 to 2944) were hospital-admitted but survived, and the remainder (51 678, 95\% CI 43330 to 60116 ) were treated in the ED and released. Firearms accounted for $95 \%$ of fatalities and $23 \%$ of hospital admissions. Virtually all other fatalities involved electromuscular disruption by tasers, with most of these deaths not immediate. Of more than 1700

Table 1 Number of people treated in hospitals or killed annually due to legal police intervention by mechanism of injury, USA

\begin{tabular}{|c|c|c|c|c|c|c|c|}
\hline Mechanism & ED & ED, also tasered* & Admitted & Fatal & Total & $\%$ admitted & $\%$ fatal \\
\hline Firearm & 1051 & 8 & 605 & 1014 & 2670 & 22.7 & 38.0 \\
\hline Explosives & 32 & & 5 & & 37 & 13.7 & 0 \\
\hline Gas & 527 & 5 & 5 & & 532 & 0.9 & 0 \\
\hline Blows & 39556 & & 1575 & & 41131 & 3.8 & 0 \\
\hline Blunt object & 2160 & 27 & 125 & 1 & 2286 & 5.5 & 0.04 \\
\hline Sharp object & 1488 & 17 & 20 & & 1508 & 1.3 & 0 \\
\hline Taser & 1639 & & 65 & 48 & 1752 & 3.7 & 2.8 \\
\hline Unspecified & 5115 & & 245 & & 5360 & 4.6 & 0 \\
\hline Late effect & 100 & & 20 & & 120 & 16.7 & 0 \\
\hline Total & 51668 & 67 & 2665 & 1063 & 55396 & 4.8 & 1.9 \\
\hline
\end{tabular}


taser-involved incidents, an estimated 65 resulted in hospital admission and 48 were lethal. Medicolegal investigations, however, concluded that the large majority of these deaths were not caused by the taser. A 2011 blue-ribbon medical panel review of medicolegal findings on deaths after electromuscular disruption suggests those determinations probably were accurate. $^{41}$

Police use of tear gas, mace or pepper spray rarely resulted in hospital admission. The large majority of non-fatal injuries stemmed from blows or blunt objects. Cases involving sharp objects generally would involve police wounding someone while seizing his or her weapon. Because the ICD lacks an appropriate cause code, these figures exclude both people bitten by police dogs, an estimated 4200 people annually (95\% CI, 2000 to 6500 ) according to 2010-2013 WISQARS online data, and injuries by mechanisms where WISQARS could not provide stable counts. WISQARS data also suggested HCUP might be underascertaining struck by/against injuries, but the WISQARS sample includes just 66 hospitals.

Estimated lifetime medical costs for injuries from legal police intervention in 2012 totalled \$231 million (2012 dollars, not tabulated). Modelled lifetime medical costs averaged $\$ 9550$ for a fatality, \$36550 for an admitted survivor and \$2390 for a patient treated in the ED and released.

In every age group, the estimated probability of hospital admission among legal police intervention injuries (5.0\%) was lower than among other assault injuries (7.5\%, not tabulated) in 2012. The AIS threat-to-life profile for legal police intervention was lower than for assaults. Among patients coded as hospital-admitted survivors of legal police intervention, $43 \%$ faced only a minor threat to life (AIS-1) and 23\% a moderate threat (AIS-2). Hospital admissions for assault and legal police intervention, however, had similar injury profiles and virtually identical modelled lifetime medical costs per case. Gunshot wounds were significantly more likely to be lethal if they resulted from legal police intervention than from assault $(40 \%$ vs $26 \%$ ).

Among patients coded as hospital-admitted survivors of legal police intervention in 2012, 49\% tested positive for alcohol, drugs or both (not tabulated). The remainder either was not tested or tested negative.

\section{Exposure and ratios of injury to exposure}

As table 2 shows, in 2012, arrests accounted for an estimated 12.3 million $(76 \%)$ police interventions with a substantial potential for violence, street stops for 2.8 million (18\%) and traffic stops involving searches for 1.0 million (6\%). The people who were least likely to be arrested when stopped were over age 65 years, Asian/Pacific Islander or living in non-metropolitan areas. Those with the highest arrest rates per 10000 population were ages 15-29 years, black or Native American.

Table 3 provides demographic breakdowns of injury counts and ratios per 10000 police stops/arrests. The differences in fatal plus non-fatal injury ratios by sex and by age group are significant at the $95 \%$ confidence level. An estimated 1 in every 291 stops/arrests resulted in a death or medically treated injury of the suspect or bystander, a ratio of 34 per 10000 stops/ arrests. The coding does not differentiate bystanders from suspects. The male injury ratio per 10000 stops/arrests was more than twice the female ratio, with even larger differentials for hospital-admitted and especially for fatal injuries. The estimated injury ratio rose initially with age, peaked at ages 30-44 years, then declined. The estimated hospital-admitted injury ratio rose steadily with age, while the estimated fatality ratio rose through age 30 years, then plateaued. Those aged 65 years and over had the highest probability of dying if injured during a stop/arrest. The injury ratio was almost three times as high in metropolitan as in non-metropolitan counties.

Both estimated hospital-admitted and fatal injury ratios per 10000 stops/arrests did not differ significantly between racial/ ethnic groups. The low hospitalisation ratio for Native Americans suggests that HCUP coding of this racial group is incomplete, with many mixed race individuals probably folded into Other Race.

\section{Uncertainty of the estimates}

The estimates reported here are far from exact. The non-fatal incident counts are constrained by identification error resulting from faulty cause coding, but SEs for these HCUP counts as coded are just $5-8 \%$ of the mean. Our denominator estimates of arrests and stops without arrest, however, have wide uncertainty ranges. SEs for the PPCS estimates in table 2 are about $10 \%$ of the mean for estimates above 1000000 but rise to $30 \%$ of the mean for estimates around $100000 .^{32}$ Worse, we can only guess at the uncertainty in the arrest count because that uncertainty results from (1) lack of reporting by some jurisdictions, even entire states, with estimating their data unavoidably requiring the questionable assumption that their arrest rates by demographics are similar to rates in jurisdictions that chose to report, and (2) an unknown amount of undercounting by some jurisdictions that did report. ${ }^{42}$

\section{DISCUSSION}

On average, an estimated 34 people were killed or medically treated for injury by law enforcement per 10000 stops/arrests. That ratio is surprisingly consistent by race/ethnicity. Blacks have high arrest and stop rates, ${ }^{43} 44$ and per capita are much more likely than whites to die at the hands of police. ${ }^{40}$ However, when blacks are stopped or arrested, they are no more likely than whites to be injured or die during that incident.

Consistent with our findings, simulation studies find police are no more likely to fire on unarmed blacks than unarmed whites, ${ }^{45}$ and high rates of black speeding citations per capita result from high violation rates. ${ }^{46-48}$ A systematic review identified 10 studies that found suspect race/ethnicity did not predict use of force or its escalation. ${ }^{6}$ However, one study found blacks were more likely than whites to face force during compliance checks. ${ }^{7}$ The PPCS survey also found that blacks were more likely to experience physical force and to perceive the threat of force during a stop, although few respondents actually were injured by the force applied. ${ }^{14}$ The large majority of incidents that those stopped perceived as undue force was stops where officers shouted at or threatened people, presumably to deter resistance.

Frequent police stops of young men have caused many black and some Hispanic mothers to teach their sons where to put their hands if approached by an officer, how to move and not move, to ask permission before reaching for their wallet, and to respond to police rudeness with respect. ${ }^{49}$ Those talks may have protective effects.

\section{High severity among the elderly}

The high hospital admission and death ratios among the injured elderly are consistent with their broader injury patterns. ${ }^{50}$ They may result from brittle bones that are vulnerable in a police scuffle. Some deaths also may represent suicidal situations where someone deliberately forces an officer to pull the trigger or an officer acts to stop a domestic murder-suicide. ${ }^{12}$ More research 
Table 2 Arrests and at-risk police stops in 2011 and rates per 10000 population

\begin{tabular}{|c|c|c|c|c|c|c|c|}
\hline & \multirow[b]{2}{*}{ Arrests } & \multirow[b]{2}{*}{ Street stops } & \multirow[b]{2}{*}{ Traffic stops with search } & \multirow[b]{2}{*}{ Total } & \multirow[b]{2}{*}{$\%$ arrested } & \multicolumn{2}{|c|}{ Per 10000 population } \\
\hline & & & & & & Arrests & Stops and arrests \\
\hline Total & 12301707 & 2839166 & 996833 & 16137706 & 76 & 510 & 668 \\
\hline Female & 3222759 & 962892 & 232201 & 4417853 & 73 & 262 & 359 \\
\hline Male & 9078948 & 1876274 & 764631 & 11719853 & 77 & 768 & 991 \\
\hline \multicolumn{8}{|l|}{ Age, years } \\
\hline $0-14$ & 369266 & & & 369266 & & & \\
\hline $15-20$ & 2551867 & 657121 & 214439 & 3423427 & 75 & 1260 & 1691 \\
\hline $21-29$ & 3821170 & 829703 & 289524 & 4940397 & 77 & 1012 & 1309 \\
\hline $30-44$ & 3478358 & 693457 & 288140 & 4459955 & 78 & 567 & 727 \\
\hline $45-64$ & 1974578 & 526885 & 186310 & 2687773 & 73 & 240 & 327 \\
\hline $65+$ & 106468 & 132000 & 18421 & 256889 & 41 & 27 & 64 \\
\hline White non-Hispanic & 5945164 & 1969371 & 509665 & 8424200 & 71 & 355 & 503 \\
\hline White Hispanic & 2420320 & 321880 & 205909 & 2948109 & 82 & 804 & 979 \\
\hline Black & 3503360 & 409551 & 229602 & 4142513 & 85 & 1187 & 1404 \\
\hline Asian/Pacific Islander & 188697 & 93553 & 27318 & 309568 & 61 & 153 & 252 \\
\hline Native American & 168941 & 40780 & 24340 & 234061 & 72 & 824 & 1141 \\
\hline Other/missing & 75226 & 4031 & 0 & 79257 & & & \\
\hline Non-metro county & 956751 & 381673 & 105067 & 1443492 & 66 & 251 & 379 \\
\hline All other & 11344956 & 2457493 & 891767 & 14694215 & 77 & 558 & 723 \\
\hline
\end{tabular}

Source: Stops tabulated from 2011 Police Public Contact Survey, arrests from 2012 Federal Bureau of Investigation (FBI) data supplemented with local 2012 data; 2012 population counts from US Census Bureau.

clearly is needed on police handling of elderly stops/arrests, and on why they often lead to serious injury or death.

\section{Judicious use of force}

A core police role has long been considered judicious but not undue use of psychological and physical force to maintain order. $^{4}{ }^{51-54}$ Police also are trained to survive. The statistics suggest that their training is largely protective, but violence occasionally escalates. ${ }^{55}$ We found that in 2012, legal police intervention resulted in an estimated 54300 people being medically treated for non-fatal injury and 1000 deaths. During 2012 an estimated 67000 law enforcement personnel were assaulted, with an estimated 18600 medically treated for injury and 48 killed $^{31}$ (FBI, 2012, tables 35 and 76, adjusted to account for non-reporting jurisdictions).

Except in firearm incidents, injuries from legal police intervention posed a lower threat to life compared with medically treated assault injuries. This finding suggests the police usually

Table 3 Number of people treated in hospitals or killed due to legal police intervention, injury ratios per 10000 stops/arrests and percentages of injuries that were fatal by demographics, USA

\begin{tabular}{|c|c|c|c|c|c|c|c|c|}
\hline & \multicolumn{3}{|l|}{ Injured } & \multicolumn{4}{|c|}{ Per 10000 stops/arrests } & \multirow{2}{*}{$\%$ Fata } \\
\hline & ED only & Admitted & Fatal & ED only & Admitted & Fatal & Total & \\
\hline Total & 51668 & 2665 & 1063 & 32.0 & 1.7 & 0.7 & 34.3 & 1.9 \\
\hline Female & 7934 & 295 & 45 & 18.0 & 0.7 & 0.1 & 18.7 & 0.5 \\
\hline Male & 43712 & 2370 & 1018 & 37.3 & 2.0 & 0.9 & 40.2 & 2.2 \\
\hline \multicolumn{9}{|l|}{ Age, years } \\
\hline $0-14$ & 763 & 30 & 1 & 20.7 & 0.8 & 0.0 & 21.5 & 0.1 \\
\hline $15-20$ & 7283 & 245 & 53 & 21.3 & 0.7 & 0.2 & 22.1 & 0.7 \\
\hline $21-29$ & 15619 & 675 & 315 & 31.6 & 1.4 & 0.6 & 33.6 & 1.9 \\
\hline $30-44$ & 18136 & 920 & 399 & 40.7 & 2.1 & 0.9 & 43.6 & 2.1 \\
\hline $45-64$ & 9329 & 665 & 268 & 34.7 & 2.5 & 1.0 & 38.2 & 2.6 \\
\hline $65+$ & 537 & 130 & 24 & 20.9 & 5.1 & 0.9 & 26.9 & 3.5 \\
\hline Non-metro county & 1485 & 90 & & 10.3 & 0.6 & & 10.9 & \\
\hline All other & 48983 & 2485 & & 33.3 & 1.7 & & 35.0 & \\
\hline White Non-Hispanics & & 1260 & 546 & & 1.5 & 0.7 & 2.2 & 30.6 \\
\hline White Hispanic & & 435 & 187 & & 1.5 & 0.6 & 2.1 & 30.1 \\
\hline Black & & 675 & 278 & & 1.6 & 0.7 & 2.3 & 29.2 \\
\hline Asian/Pacific Islander & & 50 & 20 & & 1.6 & 0.6 & 2.3 & 28.6 \\
\hline Native American & & 15 & 12 & & 0.6 & 0.5 & 1.2 & 44.4 \\
\hline Other/missing & & 230 & 20 & & & & & \\
\hline
\end{tabular}


were not out of control when they physically confronted a suspect. The Washington Post census of people killed by police estimated 74 per cent of victims were actively shooting at, aiming weapons at, or (sometimes unarmed) attacking the police. ${ }^{40}$ Still, 1 in 11 people who died due to law enforcement action in 2015 were unarmed. As case studies indicate, ${ }^{56}$ steps such as community-oriented policing, body cameras and incident investigation using surveillance methods drawn from public health may de-escalate the violence.

\section{Problems with administrative data coding and multistate analyses of firearm homicide}

Counts of Vital Statistics firearm mortality from legal police intervention are undercounts, as the newspaper enumerations showed. Vital Statistics legal police intervention appropriately excluded cases where police had been convicted, or remained under investigation, for use of excessive force (coded, respectively, as homicide and undetermined intent). They also failed to code police involvement in an estimated 450 shootings annually. If those deaths incorrectly were registered as homicides, they would artificially inflate firearm homicide counts by $4 \%$. Since misreporting rates vary widely between states, ${ }^{21}$ and may be substantially lower in NVDRS states, this problem may have skewed all recent cross-sectional time series analyses of firearm homicides. Research is urgently needed to determine the intent logged for these firearm deaths, including extending the recent capture-recapture modelling effort ${ }^{21}$ to incorporate Vital Statistics data.

Our taser counts are tenuous because neither morbidity nor mortality coding assigns a code exclusively to taser. WISQARS suggests legal police intervention was not codable for perhaps 10000 injuries, primarily from dog bites, falls or foreign bodies. Consistent with that estimate, dog bites accounted for one-eighth of all reported injuries from legal police intervention in Miami-Dade county, Florida and Richland county, South Carolina. ${ }^{57}$ The injury coding also leaves ambiguities in the unknown number of cases where police only inflicted a portion of the person's injuries. For example, if police broke up a fight by tasering a brawler who already had suffered a knife wound and a broken nose, the medical record would simply catalogue the electroshock and physical injuries, and report that they occurred in a legal police intervention incident.

\section{Other limitations}

The available arrest data are incomplete, especially information about Hispanic origin. This deficit forces us to make the imperfect assumption that available data are representative. Similarly, the sample is thin on the racial distribution of traffic stops, so the Asian/Pacific Islander and Native American estimates are unstable. ED data were not coded by race, and the coding of Native Americans was suspect in the inpatient data.

\section{CONCLUSION AND RECOMMENDATIONS}

Healthcare administrative data sets clearly have value in informing public debate about injuries resulting from law enforcement. Drilling further into the data, especially with discharge censuses rather than a national sample, linking discharges to unit record data on arrests, and possibly applying capture-recapture modelling, would detail the picture sketched here. Available state data urgently need to be tapped.

Given the frequency and potential lethality of these cases, the US clinical modification to ICD $10,{ }^{58}$ and ideally ICD10 itself, should add a code for legal intervention by taser. Legal intervention also should be a codable intent for dog bites, human bites, falls (as the PPCS finds the most common physical contact with police is a push), foreign bodies and transport.

FBI arrest data are incomplete due to late or incomplete police department reporting or refusal to report. Using local data posted to the internet, we were able to add unreported data from Alabama, Hawaii and New York City, and saw indications that the District of Columbia had the missing data in its information system. To support accurate research, on injury risk during arrest and on number of people arrested, we urge mandatory reporting of arrests to the FBI. Moreover, we strongly suggest that the FBI update its arrest data tables a year after the original closing date, in order to incorporate reports received after its deadline.

Given a national history of racism, the excess per capita death rate of blacks from US police action rightly concerns policy analysts, advocates and the press. The excess appears to reflect exposure. Blacks are arrested more often than whites, and youth more often than the elderly. However, blacks are not more likely than non-Hispanic whites to be killed or injured during a stop/arrest, and youth have the lowest injury ratios. Ratios aside, even one person unnecessarily killed or injured by the police is one too many, and every racial/ethnic group has mourned losses from undue force. As the US struggles to reduce citizen injuries during police contacts, it would seem prudent to train at-risk groups about appropriate behaviour during police stops.

\section{What is already known on this subject?}

- Minorities have a higher chance of being stopped by police, arrested and being killed by police than non-Hispanic whites.

- Untapped health data describe non-fatal injuries inflicted during legal intervention by police.

- Injury risk for those stopped or arrested by police has not been analysed.

\section{What this study adds?}

- During legal interventions in 2012 , US police fatally injured 1000 people, with an estimated 54300 surviving hospital-treated injuries.

- Estimated injury risk was 1 per 291 stops/arrests.

- While minorities were more likely to be stopped/arrested by police, the probability of being killed/injured during a stop/ arrest did not vary by race.

Contributors TRM and BAL led study conceptualisation with inputs from the other authors. BAL and SR cleaned and analysed the healthcare data. TRM analysed the PPCS and arrest data. TRM drafted the paper. All other authors reviewed it, suggested changes in analyses and presentation, and approved the final manuscript.

Competing interests None declared.

Provenance and peer review Not commissioned; externally peer reviewed.

Data sharing statement All data used are public use files available to anyone from the file distributors.

\section{REFERENCES}

1 President's Commission on Law Enforcement, Administration of Justice. Task force report: the police. Washington DC: Government Printing Office, 1967;19671:142. 
2 National Advisory Commission on Civil Disorders. Commission Report. Washington DC: Government Printing Office, 1968.

3 Collins A. Shielded from justice: police brutality and accountability in the United States. New York: Human Rights Watch, 1998.

4 Lersch KM, Bazley T, Mieczkowski T, et al. Police use of force and neighbourhood characteristics: an examination of structural disadvantage, crime, and resistance. Policing Soc 2008;18:282-300.

5 Supreme Court of the United States. United States v. Price et al., 383 US 787, 86 S. Ct. 1152; 1966 US LEXIS 1963, 1966.

6 Klahm CF, Tillyer R. Understanding police use of force: a review of the evidence. Southwest J Crim Justice 2010;7:214-39.

7 Garner JH, Maxwell CD, Heraux CG. Characteristics associated with the prevalence and severity of force used by the police. Justice Q 2002;19:705-46.

8 Police Executive Research Forum. Re-Engineering Training on Police Use of Force. Critical Issues in Policing Series. Washington DC: PERF, 2015.

9 Police Executive Research Forum. Guiding Principles on Use of Force. Critical Issues in Policing Series. Washington DC: PERF, 2016.

10 Krieger N, Chen JT, Waterman PD, et al. Police killings and police deaths are public health data and can be counted. PLoS Med 2015;12:e1001915.

11 Federal Bureau of Investigation. Crime in the United States, 2014-Expanded Homicide Data. Secondary Crime in the United States, 2014-Expanded Homicide Data 2015. https://www.fbi.gov/about-us/cjis/ucr/crime-in-the-u.s/2014/crime-in-the-u. s.-2014/offenses-known-to-law-enforcement/expanded-homicide

12 Somashekhar S, Rich S. Final tally: Police shot and killed 986 people in 2015. The Washington Post 6 January 2016.

13 Swaine J, Laughland 0, Lartey J, et al. Young black men killed by US police at highest rate in year of 1,134 deaths. The Guardian 31 December 2015.

14 Hyland S, Langton L, Davis E. Police Use of Nonfatal Force, 2002-11. Washington DC: US Department of Justice, Office of Justice Programs, Bureau of Justice Statistics, 2015

15 Agency for Healthcare Research and Quality. Nationwide Inpatient Sample. Secondary Nationwide Inpatient Sample November 2015 2015. http://www.hcup-us. ahrq.gov/nisoverview.jsp

16 Agency for Healthcare Research and Quality. Nationwide Emergency Department Sample. Secondary Nationwide Emergency Department Sample January 2016. 2016. http://www.hcup-us.ahrq.gov/nedsoverview.jsp

17 Lawrence BA, Miller TR, Weiss HB, et al. Issues in using state hospital discharge data in injury control research and surveillance. Accid Anal Prev 2007;39:319-25.

18 MacKenzie EJ, Sacco WJ. ICDMAP-90 Software: user's guide. Baltimore, MD: Johns Hopkins University and Tri-Analytics, 1997.

19 Lawrence BA, Miller TR. Medical and work loss cost estimation methods for the WISQARS cost of injury module. Final Report to the Centers for Disease Control and Prevention. Calverton, MD: Pacific Institute for Research and Evaluation, 2014.

20 Centers for Disease Control and Prevention (CDC). Web-based Injury Statistics Query and Reporting System (WISQARS), Nonfatal Injury Data. Secondary Web-based Injury Statistics Query and Reporting System (WISQARS), Nonfatal Injury Data 2016. http://www.cdc.gov/injury/wisqars/nonfatal.html

21 Banks D, Couzens L, Blanton C, et al. Arrest-Related Deaths Program Assessment. Washington DC: US Department of Justice, Office of Justice Programs, Bureau of Justice Statistics, 2015.

22 Loftin C, Wiersema B, McDowall D, et al. Underreporting of justifiable homicides committed by police officers in the United States, 1976-1998. Am J Public Health 2003:93:1117-21.

23 Planty M, Burch AM. Arrest-related deaths program: data quality profile. Washington DC: US Department of Justice, Office of Justice Programs, Bureau of Justice Statistics, 2015.

24 Barber C, Azrael D, Cohen A, et al. Homicides by police: comparing counts from The National Violent Death Reporting System, vital statistics, and supplementary homicide reports. Am J Public Health 2016;106:922-7.

25 Guardian T. The Counted: People killed by police in the United States. Secondary The Counted: People killed by police in the United States 2016. http://www.theguardian. com/us-news/ng-interactive/2015/jun/01/the-counted-police-killings-us-database

26 Rainey DY, Runyan CW. Newspapers: a source for injury surveillance? Am J Public Health 1992;82:745-6.

27 Guard A, Gallagher SS. Heat related deaths to young children in parked cars: an analysis of 171 fatalities in the United States, 1995-2002. Inj Prev 2005;11:33-7.

28 Fine PR, Jones CS, Wrigley JM, et al. Are newspapers a viable source for intentional injury surveillance data? South Med J 1998;91:234-42.

29 Berchialla P, Scarinzi C, Snidero S, et al. Information extraction approaches to unconventional data sources for "Injury Surveillance System": the case of newspapers clippings. J Med Syst 2012;36:475-81.
30 Baullinger J, Quan L, Bennett E, et al. Use of Washington State newspapers for submersion injury surveillance. Inj Prev 2001;7:339-42.

31 Federal Bureau of Investigation. Crime in the United States, 2012-Expanded Homicide Data. Secondary Crime in the United States, 2012-Expanded Homicide Data 2013. https://www.fbi.gov/about-us/cjis/ucr/crime-in-the-u.s/2012/ crime-in-the-u.s.-2012/offenses-known-to-law-enforcement/expanded-homicide/ expandhomicidemain

32 Langton L, Durose M. Police Behavior during traffic and street stops, 2011. Washington DC: US Department of Justice, Office of Justice Programs, Bureau of Justice Statistics, 2013.

33 Fuatagavi LS, Perrone P. Crime in Hawaii 2012: a review of uniform crime reports. Honolulu, HI: Department of the Attorney General, Crime Prevention \& Justice Assistance Division, Research \& Statistics Branch, 2013.

34 Alabama Statistical Analysis Center. Crime in Alabama 2012. Montgomery, AL: Alabama Criminal Justice Information Center, 2013.

35 Lindsay L. Annual report 2012. New York: Criminal Court of the City of New York, 2013.

36 Kelly RW. Crime and Enforcement Activity in New York City (Jan 1-Dec 31, 2012). New York: City of New York Police Department, 2013.

37 Lindsay L. Annual Report 2014. New York: Criminal Court of the City of New York, 2015.

38 Bratton WJ. Crime and Enforcement Activity in New York City (Jan 1-Dec 31, 2014). New York: City of New York Police Department, 2015

39 Eith C, Durose MR. Contacts between police and the public, 2008. Washington, DC: Bureau of Justice Statistics, Department of Justice, 2011

40 Kindy K, Elliott K. 987 people were shot and killed by police this year. The Washington Post 2016

41 Office of Justice Programs. Study of Deaths Following Electro Muscular Disruption. Special Report NCJ 233432. Washington DC: National Institute of Justice, 2011.

42 Maltz M. Bridging Gaps in Police Data, NCJ 176365. Washington DC: Bureau of Justice Statistics, 1999.

43 Frydl K, Skogan W, National Research Council. Fairness and effectiveness in policing: the evidence. Washington DC: National Academies Press, 2004

44 Kochel TR, Wilson DB, Mastrofski SD. Effect of suspect race on officers' arrest decisions. Criminol 2011;49:473-512.

45 Correll J, Keesee T. Racial bias in the decision to shoot? The Police Chief 2009:54-57.

46 Lange JE, Johnson MB, Voas RB. Testing the racial profiling hypothesis for seemingly disparate traffic stops on the New Jersey Turnpike. Justice $Q$ 2005:22:193-223.

47 Lundman RJ, Kowalski BR. Speeding while black? Assessing the generalizability of Lange et al.'s $(2001,2005)$ New Jersey Turnpike speeding survey findings. Justice $Q$ 2009:26:504-27.

48 Tillyer R, Engel RS. Racial differences in speeding patterns: exploring the differential offending hypothesis. J Crim Justice 2012:40:285-95.

49 Block M. 'The Talk'. How parents of all backgrounds tell kids about the police. In: Martin M, ed. All things considered. National Public Radio, 2014. http://www.npr. org/2014/09/05/346137530/the-talk-how-parents-of-all-backgrounds-tell-kidsabout-the-police (accessed 3 Jun 2016).

50 Finkelstein EA, Corso PC, Miller TR, et al. Incidence and economic burden of injuries in the United States, 2000. New York: Oxford University Press, 2006

51 Harris CJ. Police use of improper force: a systematic review of the evidence. Vict Offender 2009;4:25-41.

52 Klockars CB. The idea of police. Beverly Hills, CA: Sage Publications, 1985.

53 Bittner $\mathrm{E}$. The functions of the police in modern society. Washington DC: National Institute of Mental Health, Center for Studies of Crime and Delinquency, 1970.

54 Alpert GP, Dunham RG. Understanding police use of force: Officers, suspects, and reciprocity. Cambridge University Press, 2004.

55 MacDonald JM, Manz PW, Alpert GP, et al. Police use of force: examining the relationship between calls for service and the balance of police force and suspect resistance. J Crim Justice 2003;31:119-27.

56 Prenzler T, Porter L, Alpert GP. Reducing police use of force: case studies and prospects. Aggress Violent Behav 2013;18:343-56.

57 Smith M, Kaminski R, Alpert G, et al. A Multi-Method Evaluation of Police Use of Force Outcomes: Final Report to The National Institute of Justice, Document 231177, 2010.

58 Annest J, Hedegaard $\mathrm{H}_{1}$ Chen $\mathrm{L}$, et al. Proposed framework for presenting injury data using ICD-10-CM external cause of injury codes. Atlanta, GA: National Center for Injury Prevention and Control, National Center for Health Statistics, Centers for Disease Control and Prevention, 2014. 